\title{
An Exploratory Case study of the effect of Ecology on Malaria Risk Factors in Northern Pakistan.
}

QAISAR JAMAL

Department of Zoology, University of Peshawar.

Syed Basit Rasheed ( $\sim$ basitrasheed@uop.edu.pk)

University of Peshawar https://orcid.org/0000-0002-3080-411X

NAZMA HABIB KHAN

University of Peshawar

FARRAH ZAIDI

University of Peshawar

NAZIA NAZ

University of Peshawar

SUMBAL ILTAF

University of Peshawar

MUHAMMAD ADNAN

University of Peshawar

Gule Tanzila

University of Peshawar

Israil .

University of Peshawar

MUHAMMAD ZAHID

Islamia College Peshawar

QAISAR ZAMAN

University of Peshawar

\section{Case study}

Keywords: Charsadda, Swabi, ecology, malaria transmission, risk factors

Posted Date: February 20th, 2020

DOI: https://doi.org/10.21203/rs.2.24018/v1

License: (c) (1) This work is licensed under a Creative Commons Attribution 4.0 International License. Read Full License 


\section{Abstract}

Background. Ecology of an area can greatly affects the population of the vector mosquito species by providing conditions for their breeding, thus affecting the transmission of malaria in an area. Areas having similar climate, but dissimilar ecological conditions may alter the factors of malaria transmission, thus resulting in different control strategies for disease management. Current study implies a crosssectional approach to investigate different malaria risk factors in two ecologically distinct districts of Khyber Pakhtunkhwa, Pakistan.

Methods: Data was collected by using closed-ended questionnaire from 2854 and 1944 randomly selected individuals of District Charsadda and Swabi respectively from December to August. A univariate logistic regression analysis was used to measure the association between history of malaria infection and different possible risk factors.

Results: $37.6 \%$ of the respondents in Charsadda and $46.5 \%$ in Swabi were having history of malaria infection. Plasmodium vivax was found to be the dominant species causing infection in the local population. In district Swabi, factors like windows mesh, drinking water source, irrigated fields, sleeping habits, gender and marital status was found significant $(P<0.05)$ in the transmission of the infection. In district Charsadda, parameters like windows mesh, house made, animals in home, irrigated fields, use of residual sprays, use of repellents, use of bed nets, outdoor night roaming, family history, previous infection and sleeping habits showed significant $(P<0.05)$ relation to malaria infection.

Conclusions: This study provides some basic guidelines by identifying the potential risk factors in districts having diverse ecology to design a comprehensive and effective control strategy to reduce malaria disease burden.

\section{Background}

Malaria is endemic in approximately 130 countries around the world. The disease results in mortality and severe disability among the afflicted communities, particularly in Africa. In 2001, the World Health Organization (WHO) ranked malaria as the eight highest contributors to the global disease burden as reflected in disability-adjusted life years (DALYs), and the second highest in Africa. There are about 300 to 500 million malarial infections and 1 million malaria attributed deaths worldwide each year. About $90 \%$ of these deaths occur in Sub-Saharan Africa, and most of them occur among women and children [1, 2]

Ninety-five million of Pakistan's more than 190 million people, roughly $60 \%$ of the country population, live in malaria-endemic regions. In recent years, an increase in malaria cases can be partially attributed to floods that affected approximately 20 million people in over 60 districts. Despite a well-established malaria control programme, 500,000 malarial infections and 50,000 malaria attributed deaths occur each year in Pakistan, with approximately $37 \%$ of cases estimated to occur in regions along the border with Afghanistan and Iran [2]. 
Plasmodium vivax (responsible for approximately $80 \%$ of infections) and Plasmodium falciparum (causing 20\% of infections) are the two prevalent Plasmodium species in Pakistan [3]. Malaria transmission is unstable, with major Plasmodium vivax transmission peaking from June to September and again in April to June, when relapses of infections acquired in the previous seasons are observed. The major transmission period for Plasmodium falciparum in Pakistan is between August and December [4].

Although majority of malaria in Pakistan is caused by Plasmodium vivax, however trend in past few decades have indicated that Plasmodium falciparum infection is on the rise. In 2010, 73,857 (31\%) of 240,591 total reported malaria cases in Pakistan were Plasmodium falciparum [5]. The rise of Plasmodium falciparum in parts of Pakistan may partially be attributable to the failed treatment of chloroquine resistant infection. Monitoring the distribution and burden of Plasmodium species in Pakistan, as changes occur in both human and parasite population is necessary to ensure appropriate treatment, particularly in situations where diagnosis by microscopy or species specific rapid diagnostic test is not available [4].

In Pakistan out of 23 species of Anopheles [6], only few species act as vector of Plasmodium and can transfer this protozoan parasite from one human to another. An. stephensi has been considered as major vector of malaria in urban where as An. culicifacies act as vector of this disease in rural areas [7]. Other species like An. maculatus, An. nigerimus, An. superpictus and An. subpictus in Baluchistan [8], while An. fluviatilus, An. splendidus, An. stephensi and An. culicifacies have been regarded as vector of malaria in Charsadda district of Khyber Pakhtunkhwa through serological tests and systematic operational research [9]. In Swabi both An. stephensi and An. culicifacies have been reported from malaria endemic area of the district [10] but no study has been conducted to date regarding incriminating the vector of malaria in the district.

Keeping in view the ecological differences between the districts of Charsadda and Swabi, present study was designed to know the period prevalence of malaria in these two malaria endemic areas of KP along with identifying the risk factors associated with the transmission of diseases in the study area.

\section{Methods}

\section{Study Area}

Khyber Pakhtunkhwa (KP) is one of the four administrative provinces of Pakistan located in the north west of Pakistan. Administratively it was divided into 27 districts but after the merger (KP-FATA) of Federally Administered Tribal Areas (FATA) the number of districts increased to 34. Both KP and FATA have malaria endemic regions. Two Districts of KP: Charsadda and Swabi (Fig. 1) were selected for malaria risk factor analysis. District Swabi has an area of 1,543 sq. km having a population of 1,624,616 while District Charsadda has an area of 996 sq. km having a population of 1,616,198. Both districts have extreme climate with hot summers and cold winters. There are two spells of rainy season in a year, the 
winter rain due to western disturbance and summer rains due to monsoon, that persist from July to September when the temperature is hot and humid resulting in maximum transmission of malaria in the region.

Charsadda and Swabi are two agricultural districts of Khyber Pakhtunkhwa (KP). Though not located far away from each other and separated by district Mardan only and have similar climatic conditions but they are ecologically distinct. Charsadda known as land of rivers has River Swat, River Kabul, Jindi and Landai rivers, upper and lower Swat canals, Michini Dalazak canal and Doaba feeder canal, which are the main source of irrigation in the area. Due to these water bodies the land of Charsadda is water logged [11].

On the contrary Swabi is also an agricultural area. River Indus flows along the southern boundary of the district and small streams like Badrai, Narranji, Shagai and Pehur high level canal are used to irrigate fields of the district but there are some areas (arid areas) of the district where irrigation is not feasible and are used for dry farming of crops or tube wells are used for irrigation [12]. Comparatively dry nature of Swabi and water logging of Charsadda may be playing an important role in differentiation of the factors for transmission of malaria.

\section{Questionnaire Design}

A questionnaire was designed to assess the associated risk factors in both districts. The questionnaire has three main parts: first part was regarding sociodemographic characters such as age, gender, education level, occupation, and employment status. Second part focused on exposure of human population to the vector mosquitoes like presence of animals in house, water storage activities, outdoor roaming late night, type of house building material, presence of agricultural fields near the houses and sleeping habits while the last part described the prevention activities like use of bed nets, windows mesh, repellents and insecticides to prevent interaction with mosquitoes. Information regarding malaria family history and previous infection was also gathered through the questionnaire. Objectives of the study were clearly explained and consent on the questionnaire was obtained from each participant with the assurance that the privacy of the data obtained through questionnaire will be maintained. Each participant was asked that either they had suffered from malaria during last one year to know about the malaria case history in the districts. Focus for filling the questionnaire were on those areas which have high incidence of malaria in each district.

\section{Data analysis}

Statistical analysis was performed using SPSS version 20. For determining the association between malaria prevalence and potential risk factors, a univariate analysis was performed using logistic regression together with their $95 \%$ confidence interval. Map showing the study area was prepared using ArcGIS version 10.2.2. 


\section{Results And Discussion}

A total of 2854 individuals from Charsadda and 1944 individuals from Swabi were included in the survey. Characteristics of the individuals from both districts included in the survey are given in Table 1. In district Charsadda 1073 out of 2854 (37.6\%) individuals showed malaria case history while in Swabi 905 out of 1944 (46.5\%) individuals were having history of malaria disease. Not all the respondents were having information regarding the species of Plasmodium causing the disease but among the positive cases having the test reports, Plasmodium vivax was found to be the dominant species with $81.4 \%$ cases while P. falciparum was represented by $18.6 \%$ cases.

Regarding various factors related to chance of getting malaria infection in district Swabi, being male, married, having water tanks and tube wells as water source, working in irrigated fields and sleeping outside during night significantly increase the risk of having malaria. On the other hand, living in households with meshed windows seemed protective and significantly lower the malaria risk (Table 2). In district Charsadda, the univariable analyses revealed that working in irrigated fields, living in mud walled houses, sleeping outdoors, presence of animals in houses, sleeping outdoors and roaming at night results in significantly higher odds of acquiring malaria. Similarly, having past infection of malaria and living with family members with history of the disease have been associated with increased risk of malaria. Ownership of meshed windows and use of protective means such as bed nets, repellents and residual sprays apparently reduce malaria risk (Table 2$)$. In Charsadda sleeping habits $(O R=4.05)$, irrigated fields $(\mathrm{OR}=3.37)$, mud house type $(\mathrm{OR}=1.53)$, late night roaming $(\mathrm{OR}=1.52)$ and family malaria history $(\mathrm{OR}=$ 1.27), while in Swabi drinking water source $(O R=1.77)$, irrigated fields $(O R=1.7)$ and sleeping habits (OR $=1.29)$ are playing more important role in malaria transmission.

In this study, prevalence rate of malaria and risk factors associated with malaria transmission were studied in two ecologically distinct districts: Charsadda and Swabi, of Khyber Pakhtunkhwa, Pakistan. Ecology of an area greatly influence the mosquito density due to availability of breeding habitats and ultimately transmission of malaria. In Charsadda as well as in Swabi majority of the cases were of Plasmodium vivax. Plasmodium vivax and Plasmodium falciparum are transmitted by Anopheles species, but Plasmodium falciparum has been deemed responsible for $99 \%$ of the deaths due to malaria $[2,13]$. During current study, in majority of malaria cases the causative agent was reported to be Plasmodium vivax which is similar to other findings which report that $80 \%$ of the cases reported in the country belong to Plasmodium vivax while $20 \%$ are caused by Plasmodium falciparum [3].

Current study shows that proper use of barriers like windows screening, housing types and bed nets significantly reduce the incidence of malaria. Window screening though a simple method but offered a formidable barrier to the vectors of malaria and indoor sleeping has been considered beneficial in minimizing the transmission of malaria $[14,15]$. Studies have shown a $50 \%$ reduction in indoor vector density and ultimately reduction in malaria due to screening of doors and windows [16]. Present study showed that in both districts; Charsadda and Swabi, a significant reduction in malaria cases (143 and 365 cases having windows mesh as compared to 930 and 520 cases having no windows mesh) have 
been observed due to use of window screening, though this factor has little contribution to the malaria transmission in both districts ( $O R=0.144$ and 0.379 for Charsadda and Swabi respectively). Majority of positive malaria cases have been observed among households not having windows mesh to prevent entry of vector mosquito into the house and reduce malaria transmission in the area. Thus, presence of windows mesh plays an important role in reducing malaria case burden in malaria endemic areas.

Along with screening windows and doors, modifying the building architecture [17] and good house construction [18] may help in minimizing risks of malaria infection in disease endemic areas. These strategies could also minimize human-vector interaction, thus resulting in reduction of the disease burden in the endemic areas. In our study malaria cases were also found to be significantly associated with house type. The odds of malaria infection were found to be twice as high among houses made of mud $(\mathrm{OR}=1.53)$ in Charsadda, while no association have been observed in Swabi. Houses having good construction (brick made) were having significantly low malaria cases as compared to houses having mud walls and thatched roofs. Mud walled and thatched roof houses provide favourable conditions to vector mosquitoes for resting and taking refuge in the cracks, crevices and thatched roofs. Living in towns and in indoor setting significantly reduce the malaria transmission [19]. House construct plays an important role in determining the frequency of mosquito bites and their vectoral potential because such houses provide less resting and refuge places for the vector [20]. People in rural settlements and peripheral populations of towns have been found more vulnerable to malaria due to inadequate house construct and improper sanitation [21]. Both our study districts have more rural settlements but district Charsadda is almost all rural except the town of Charsadda, which may be the reason that houses having mud wall construction play a significant role in malaria transmission in Charsadda.

Using insect repellents, indoor residual spray (IRS) and insecticide treated bed nets reduce the chances of getting infected with malaria [22]. In Pakistan Deltamethrin wettable powder is used for IRS and temephos is used as larvicide as per WHO guidelines while the only insect repellent available is in the name of Mospel (Diethyltoluamide) by Abbott laboratories Pakistan. However, the use of these insecticides was variable in both districts. In Charsadda the odds of getting malaria infection was low but significant for those who use repellents, IRS and bed nets ( $O R=0.116,0.062$ and 0.166 respectively). Charsadda being waterlogged provide abundant sites for mosquito breeding resulting in high abundance of mosquitoes, therefore using insect repellents, bed nets and IRS is a common practice in the area, which helps in reducing mosquito densities thus resulting in low transmission of the disease in households using these strategies. On the contrary Swabi have canal irrigation and dry areas, not providing abundant breeding sites like Charsadda, so insecticide use in various form was found infrequent in the people of the study area and no association has been observed between them and malaria occurrence. In addition, in Charsadda government organization like roll back malaria program and international organizations like global fund carry out IRS programs and distribute bed nets among the locals [23] which may be contributing towards the reduction in disease burden. On the other hand, no such organized activity either by government or NGOs happened in Swabi and locals carry out their own IRS activity, which may be the reason of these factors not playing any significant role in malaria transmission in Swabi. 
Ecology of an area effects the vector abundance by providing breeding habitat for the mosquitoes [24]. Water storage activity has been associated with malaria occurrence [25] and has been found significant in Swabi only. The odds of malaria infection were found to be twice as high $(O R=1.8)$ for those households using water storage containers in Swabi. Charsadda being water logged provide enough breeding sites for mosquitoes so presence of water storage container does not have significant effect on the occurrence of malaria in the study area, on the contrary, lack of abundant breeding sites due to arid area and canal system does not provide enough egg laying opportunities all the year around for mosquitoes, diverting them to breed in water storage containers [26]. Irrigated fields also play an important role in breeding of the mosquitoes and has been observed to increase the odds of getting malaria three times in Charsadda $(O R=3.37)$ and twice in Swabi $(O R=1.7)$. It has been reported that stream bed pools used for irrigation act as an important source of Anopheles culicifacies breeding during dry period resulting in seasonal peak of malaria cases [27]. Charsadda and Swabi being agricultural districts depends upon canals and streams for irrigation, which can provide breeding grounds for vector mosquitoes thus playing significant role in malaria transmission in both districts. Sleeping outside has been observed to play a major role in malaria transmission in Charsadda by getting the odd ratio of malaria four times $(O R=4.05)$ higher for sleeping outside at night as compare to Swabi $(O R=1.3)$. Sleeping habits was also found significantly associated with malaria incidence in the study area. Outdoor sleeping increases the incidence of malaria due to exposure to vector mosquitoes as use of window mesh can prohibit mosquito entrance into the rooms thus decreasing mosquito-human interaction.

Domestic animals may minimize disease transmission in the sense that they provide an alternative host for the mosquito vector to meet its blood meal requirement. It has been noted in a study in Keerom, Indonesia where most of the people keep their animals around their houses [28]. In Swabi presence of domestic animals has not been significantly associated with malaria risk but significant association has been observed in Charsadda where presence of domestic animals increases the occurrence of malaria. As it has been discussed afore that domestic animals attract vector mosquitoes and house construction type provide refuge to indoor resting mosquitoes, both these conditions have been found associated with malaria in Charsadda only, thus house type and domestic animals combine effect increase the risk of malaria in the district.

\section{Conclusion}

Vector borne diseases like malaria can be controlled by minimizing the human-vector interaction through reducing the vector densities. Our study identified the risk factors responsible for the incidence of malaria in the study area. Using this information in formulating a strategy to control vector population and decreasing malaria occurrence in the study area can help in saving lives. Controlling the vector population by physically destroying the breeding habitats along with wise use of insecticide and convincing people to change their behaviour like sleeping habits, late outdoor roaming, use of windows mesh and bed nets can help in decreasing disease burden in the study area. 


\section{Declarations}

\section{Ethical Approval and Consent to Participate}

A consent to use the data for research and publication was taken from all the participants before collecting data for the use of research purpose.

\section{Consent for Publication}

The corresponding author on the behalf of all authors here by declare the consent for publication.

\section{Availability of Data and Material}

The authors hereby have included all the data and material in the manuscript.

\section{Competing Interest}

None declared.

\section{Funding}

Funding source: none

\section{Authors contribution}

QJ and SBR conceived and prepared the study design and wrote the article. NN and SI collected the data. SBR and NHK analyse the data.FZ, MA, GT, I, MZ and QZ helped in collecting the data and editing the article.

\section{Acknowledgements}

The authors are thankful to the local elders for helping in smooth conduction of the survey in both districts.

\section{References}

1. Sahar, S., Tanveer, A., Ali, A., Bilal, H., Saleem, R. M. 2015. Pfcrt gene in Plasmodium falciparum field isolates from Muzaffargarh, Pakistan. J Arthropod-Borne Di. 9(2): 204-214.

2. World Health Organization (WHO). 2017. World Malaria Report 2017; WHO Press: Geneva, Switzerland, 33-41.

3. Javid K, Umer, I., Jan, S. U., Jan, F. U., Ghaffar, I., Rehman, M., Khan, M. A., Hayat, A., Qasim, M., Hussain, M. 2015. Prevalence of malaria in local population of district Kohat, Khyber Pakhtunkhwa, Pakistan. J of BioMol Sci. 3:113-8. 
4. Khattak, A.A., Venkatesan, M., Nadeem, M. F., Satti, H. S., Yaqoob, A., Strauss, K., Khatoon, L., Malik, S. A., Plowe, C. V. 2013. Prevalence and distribution of human Plasmodium infection in Pakistan. Malaria J. 12:297. doi:https://doi.org/10.1186/1475-2875-12-297

5. Kakar, Q., Khan, M. A., Bile, K. M., 2010. Review: Malaria control in Pakistan: new tools at hand but challenging epidemiological realities. E Mediterr Health J. 16 (Supplement): S54-S60.

6. Aslamkhan, M., 1971. The Mosquitoes of Pakistan. A Checklist. Mosq. Syst. Newsl., 3:147-159.

7. Ali, N. and Rasheed, S.B. (2009). Determination of species composition of mosquitoes found in Palosai stream, Peshawar. Entomol. 30(1): 47-51.

8. Anonymous 2014. Country Coordinating Mechanism Pakistan. National Institue of Health, Pakistan.

9. Ali, N., Noreen, S., Khan, K. and Wahid, S. 2015. Population dynamics of mosquitoes and malaria vector incrimination in district Charsadda, Khyber Pakhtunkhwa Pakistan. Acta Trop. 141: 25-31.

10. Yousafzai, A.Z.K. 1994. Ecological studies on mosquitoes in a rural village of Swabi district", M.Sc. Thesis, Department of Zoology, University of Peshawar, Pakistan

11. 2000a. 1998 District Census Report of Charsadda. Census Publication no 62. Population Census Organization, Statistic Division, Government of Pakistan, Islamabad, p. 1-7.

12. 2000b. 1998 District Census Report of Swabi. Census Publication no 83. Population Census Organization, Statistic Division, Government of Pakistan, Islamabad, p. 1-7.

13. Gunda, R., Chimbari, M. J., Shamu, S., Sartorius, B., Mukaratirwa, S. 2015. Malaria incidence trends and their association with climatic variables in rural Gwanda, Zimbabwe, 2005-2015. Malaria J. 16: $1-13$.

14. Kirby M. J., Green, C., Milligan, P., Sismanidis, C., Jasseh, M. et al. 2008. Risk factors for house entry by malaria vectors in a rural town and satellite villages in The Gambia. Malaria J. 7: 2. doi: 10.1186/1475-2875- 7-2 PMID: 18179686.

15. Ogoma S. B., Lweitoijera, D. W., Ngonyani, H., Furer, B., Russell, T. L. et al. 2010. Screening mosquito house entry points as a potential method for integrated control of endophagic filariasis, arbovirus and malaria vectors. PLOS Neglect Trop D. 4: e773. doi:10.1371/journal.pntd.0000773 PMID: 20689815.

16. Kirby M. J., Ameh, D., Bottomley, C., Green, M. Jawara et al. 2009. Effect of two different house screening interventions on exposure to malaria vectors and on anaemia in children in The Gambia: a randomized controlled trial. Lancet 374: 998-1009. doi: 10.1016/S0140-6736(09)60871-0 PMID: 19732949

17. Bradley, J., Rehman, A. M., Schwabe, C., Vargas, D., Monti, F., Ela, C., Riloha, M., Kleinschmidt. I. 2013. Reduced prevalence of malaria infection in Children Living in Houses with Window Screening or Closed Eaves on Bioko Island, Equatorial Guinea. PLoS ONE 8(11): e80626. doi: 10.1371/journal.pone.0080626.

18. Wanzirah H, Tusting, L. S., Arinaitwe, E., Katureebe, A., Maxwell, K., Rek, J., Bottomley, C., Staedke, S. G., Kamya, M., Dorsey, G., Lindsay, S. W., 2015. Mind the Gap: House Structure and the Risk of Malaria in Uganda. PLoS ONE 10(1): e0117396. doi:10.1371/journal.pone.0117396. 
19. Snyman, K., Mwangwa, F., Bigira, V., Kapisi, J., Clark, T. D., Osterbauer, B., Greenhouse, B., Sturrock, H., Gosling, R., Liu, J., Dorsey, G. 2015. Poor Housing Construction Associated with Increased Malaria Incidence in a Cohort of Young Ugandan Children. Am J Trop Med Hyg. 92 (6): 1207-1213.

20. Charlwood, J.D., Pinto, J., Ferrara, P. R., Sousa, C. A., Ferreira, C., Gil, V., do Rosário, V. E. 2003. Raised houses reduce mosquito bites. Malaria J. 2: 45 http://www.malariajournal.com/content/2/1/4.

21. Castilo-Salgado. C. 1992. Epidemiological risk stratification of malaria in the Americas. Mem I Oswaldo Cruz, Rio de Janeiro 87 (III): 115-120.

22. Dawaki, S., Al-Mekhlaf, H. M., Ithoi, I., Ibrahim, J., Atroosh, W. M., Abdulsalam, A. M., Sady, H., Elyana, F. N., Adamu, A. U., Yelwa, S. I., Ahmed, A., Al-Areeqi, M. A., Subramaniam, L. R., Nasr, N. A., Lau, Y. 2016. Is Nigeria winning the battle against malaria? Prevalence, risk factor and KAP assessment among Hausa communities in Kano State. Malaria J. 15: 351.

23. Munir, M.A., Qureshi, H. and Safdar, N. 2014. Malaria indicator survey in 38 high risk districts of Pakistan. Directorate of Malaria Control. Pakistan Medical Research Council. Pakistan. pp 45-54.

24. Ferraguti, M., De La Puente, J. M., Roiz, D., Ruiz, S., Soriguer, R., Figuerola, J. 2016. Effects of landscape anthropization on mosquito community composition and abundance. Sci Rep-UK, 6, 29002; doi: 10.1038/srep29002.

25. Idowu, O. A. 2014. Effect of environmental hygiene water storage on the prevalence of malaria among pregnant women in Abeokuta, Nigera. Health. 6(1): 90-93.

26. Nilsson L.K., Sharma, A., Bhatnagar, R. K., Bertilsson, S., Terenius, O. 2018. Presence of Aedes and Anopheles mosquito larvae is correlated to bacteria found in domestic water-storage containers. FEMS Microbio Ecol. 94(6): doi:ttps://doi.org/10.1093/femsec/fiy058

27. Amerasinghe F. P., Konradsen, F., Fonseka K.T., Amerasinghe, P.H. 1997. Anopheline (Diptera: culicidae) breeding in a traditional tank-based village ecosystem in north central Sri Lanka. J. Med Entomol. 34: 290-97.

28. Sandjaja, B., Noor, N. N., Arsin, A. A., Nurdin, A., 2014. Dominant Malaria Risk Factors in Keerom Papua, Indonesia: A Prospective Cohort Study Analyzed by Multivariate Logistic Regression. Int J Sci Res Pub 4 (3): ijsrp.org.

\section{Tables}

Due to technical limitations, Tables $1 \& 2$ are only available for download from the Supplementary Files section.

\section{Figures}




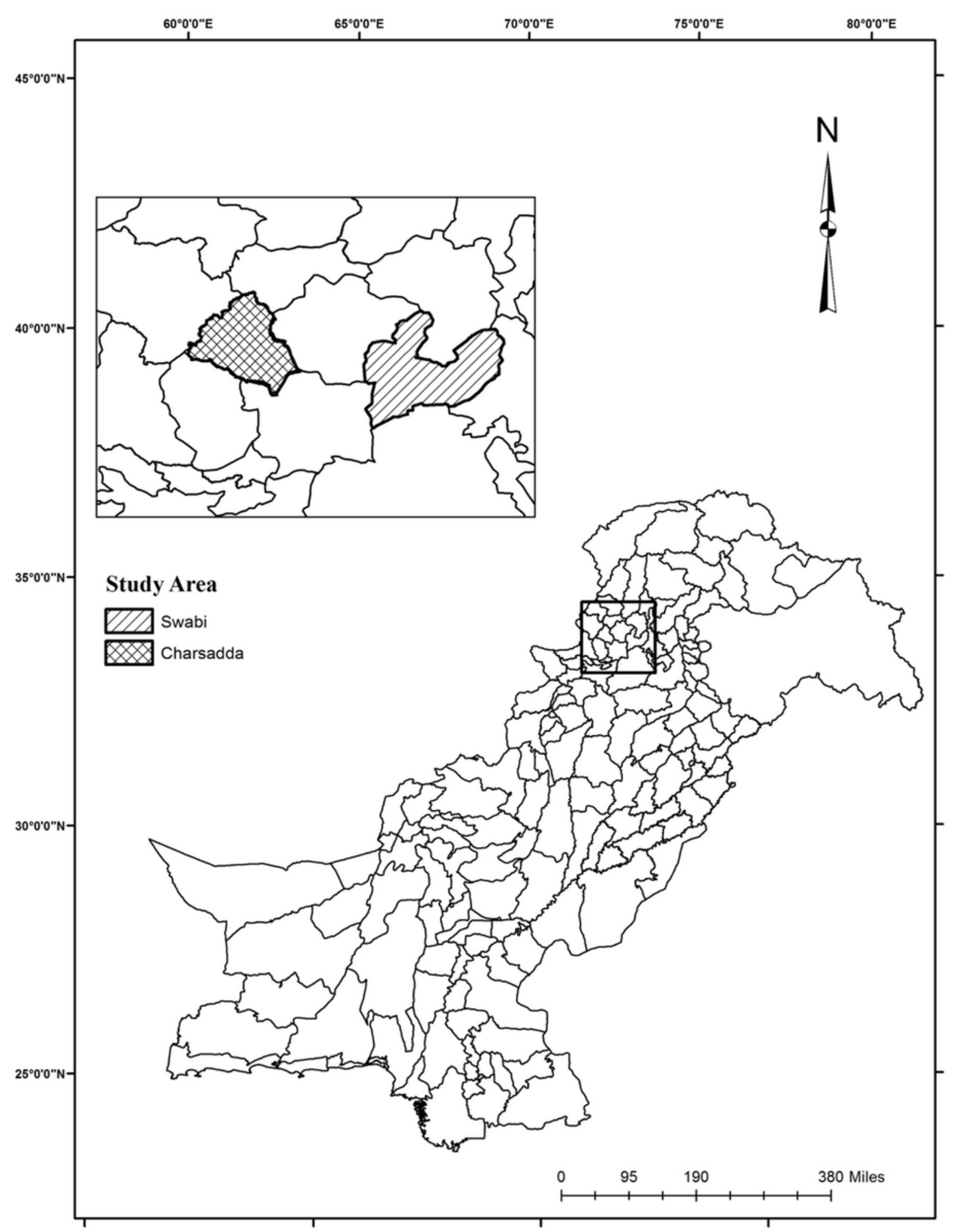

Figure 1

Map showing study area in Pakistan.

\section{Supplementary Files}

This is a list of supplementary files associated with this preprint. Click to download. 
- Table1.pdf

- Table2.pdf

Page 12/12 